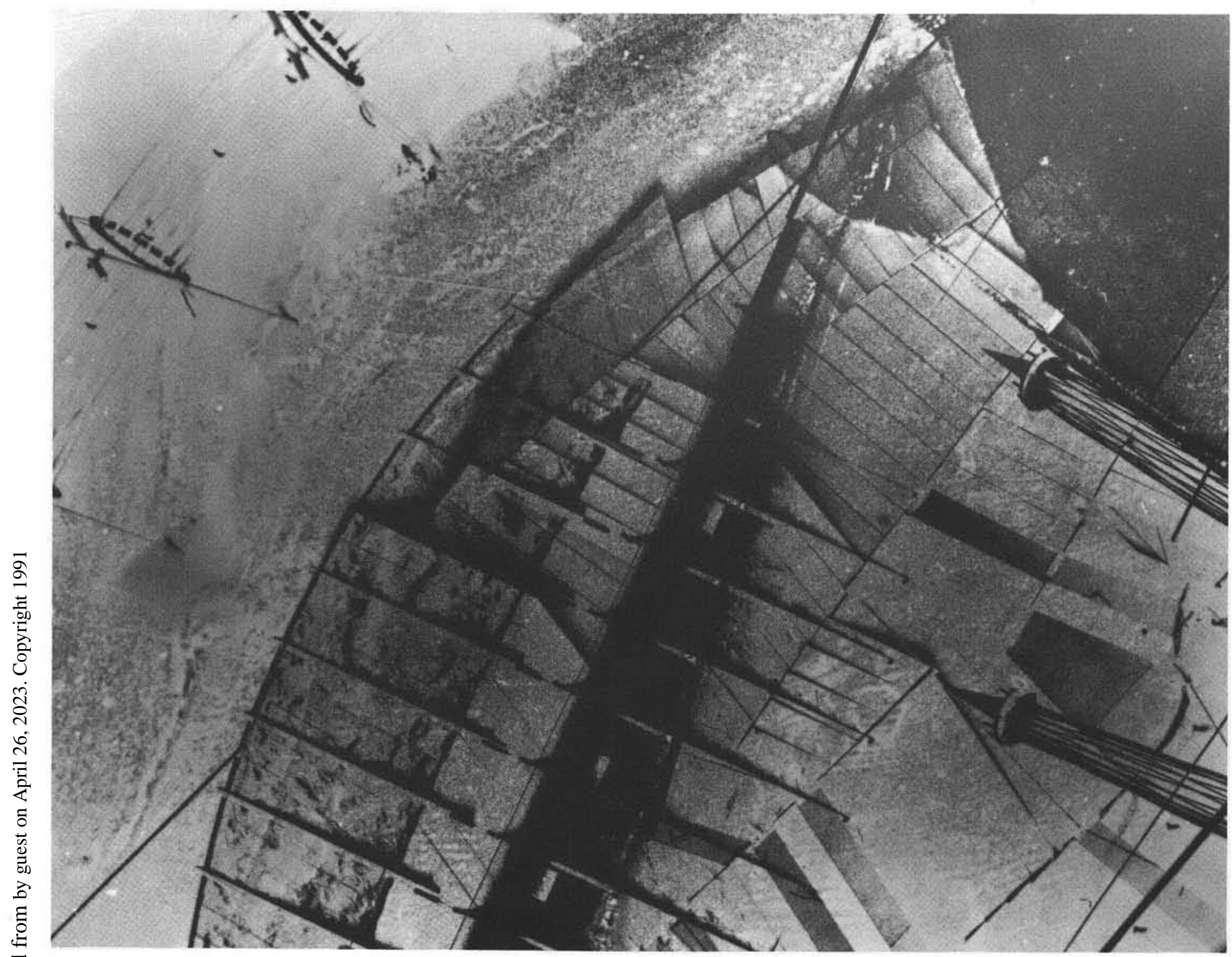

Dan Hoffman's investigations of sublime landscape find sources in the descriptions of vast "desert seas" that were encountered in the transcontinental survey of the 35 th parallel made in the middle of the nineteenth century. See Lance Neckar, "Two Near Voids." 


\section{The Avant-Garde and the Landscape: Guest Editors' Introduction}

$\mathrm{T}$ he specialness of this issue of Landscaape Journal is both circumstantial and substantive. It originated in a highly orchestrated but transitory event. It has come to this state through the force of the ideas herein. The papers were written for the "The Avant-Garde and the Landscape: Can They Be Reconciled?" conference, held in 1989 at the University of Minnesota College of Architecture and Landscape Architecture. Each author responded to the same set of questions posed in the call for papers by Professors Patrick Condon, Lance Neckar, and Garth Rockcastle, the conference organizers. There is therefore an obvious relationship among the papers that is not typical of the Journal.

Although each of the articles can stand alone, in this issue they are also tied together thematically; they are all about the landscape as relative phenomena-and by extension, about our relative control of these phenomena. By "relative" we mean this: of all the different venues for phenomena, landscape is the venue where contingencies, whether temporal, cultural, perceptual, botanical, or historic, always exert relatively powerful influences; they do so to the point where the discussion of landscape in absolute terms becomes exceedingly problematic. In this group of papers, the opportunities and paradoxes of relative control are pointed out via the thematic focus of avant-gardism.
For instance, because "immediacy" has been declared by the theorists to be one of the characteristic features of avant-garde work, what happens when the temporally and spatially open and continuous landscape is treated "immediately" in terms common to sculpture, that is, that which is nearly always temporally and spatially more fixed? Obviously this creates the possibility for direct, even irritated discussion. Such direct and irritated discussion occurs in the way that the articles herein have been arranged: the papers have been ordered sequentially in such a way that they speak to one another and may thus be read as a book, albeit a book with a necessarily inconclusive ending.

The overall scheme is as follows.

The introductory pieces by Lance Neckar and Patrick Condon, written in the broadest strokes they could muster, reveal how they as guest editors understand this issue. They attempt to set out why the issue of the avant-garde and the landscape matters to the discipline of landscape architecture specifically and the culture that landscape architecture touches more generally. Then, the more pointed and fully elaborated ideas are given their places.

To begin, Garrett Eckbo's paper is both a recollection of his avant-garde voice in the 1930s and 1940s and his enlarged vision as an avant-garde in the difficult world of today. It is a window on the ideas of our own modernity, historical and contemporary.

Sidney Robinson's paper on the Picturesque (re)defines the phenomenon in a scholarly way that suggests both its avant-garde characteristics in its time and its role as the source of appropriate relativity/ism in our discipline. Robinson's paper responds to the 
Modernists' trashing of history in general and the Picturesque more specifically and sets the stage for an understanding of the critical departure of J. C. A. Alphand from the Picturesque in his work at Buttes-Chaumont.

Beth Meyer's paper places Alphand in the context of an avantgarde approach to landscape as "systems" by a "dogmatic" comparative study of Bernard Tschumi's ideas at Parc de la Villette.

Douglas Paterson's stormy essay on the battles to restore landscape as life-giving force and to revive the experience and meaning of landscape speaks to issues identified by Meyer as missing from Tschumi's "system," and prepares the ground for the deployment of "combatants" in both of the battles.

John Lyle speaks primarily to the first battle, evoking the possibility of deep landscape that resolves our position amid nature. Our battle here is to let nature do what it must in order to deepen us.

Peter Jacobs places landscape in a quaternary field that is defined by dichotomous axes-nature:not nature and culture:not culture. Landscape occurs here on a perpendicular axis between nature and culture; and by the casting of his paper, Jacobs reflects on opportunities to (re)form landscape as the cultural dialectical product of (de)forming and (in)forming landscape. Using another explanatory quaternary field, Jacobs also places landscape architecture (logically) between the poles of landscape and architecture. This field was originally devised by Rosalind Krauss, and she has placed "site constructions" on this axis.
The power of "site constructions" is explored by David Merrill, who engages them on their terms (as art in/of landscape) in order to compare them to "marked sites" (which reside between the poles of landscape:not landscape); and he thereby reveals the potential of "site constructions" and their related phenomenon, landscape architecture. Iain Robertson takes us beyond earthwork and its seductive powers to the difficult but potent world of plants that so many practitioners have left behind, suggesting their difficulty and potential as an avant-garde medium of relative control in the cause of (re)forming landscape.

And so by grouping the papers in this order, the conversation on the possibilities of the avant-garde has developed; yet the central questions-about theory-making and application in an apparently relative realm - are given some irritative prodding.

Patrick M. Condon

Lance Neckar 